\title{
Uso das técnicas por diafanização e modelagem matemática em 3D como métodos de contribuição e identificação foliar de Protium ovatum Engl.
}

\section{Use of diaphanization techniques and 3D mathematical modeling as methods of contribution and leaf identification of Protium ovatum Engl.}

\author{
Antonio Carlos Pereira de Menezes Filho ${ }^{1}$ \\ 'Mestre em Agroquímica, pelo Instituto Federal Goiano, campus Rio Verde - GO, Brasil. E-mail astronomoamadorgoias@gmail.com *Autor \\ para correspondência
}

\author{
Palavras-chave \\ F.E.V.S \\ Nervação \\ Protium ovatum \\ Diafanização foliar \\ Análise foliar
}

\begin{abstract}
O trabalho teve por objetivo o uso das técnicas por diafanização e modelagem matemática em 3D como métodos de contribuição e identificação foliar de Protium ovatum Engl. Folhas de P. ovatum foram coletadas em uma área de Cerrado no município de Rio Verde, GO, Brasil. As lâminas foliares foram diafanizadas com azul de toluidina, violeta de genciana, azul de metileno, safranina e fucsina fenólica. Foi realizado o escaneamento e micrografias ópticas, e modelagem matemática em 3D, utilizando imagens no negativo, invertidas e filtros XYZ. Foram obtidos resultados importantes para a identificação acurada da espécie $P$. ovatum por diafanização foliar e com artifícios matemáticos em 3D. Foram observados 3 pares de folíolos, tricomas glandulares apenas na face adaxial e tectores na abaxial, estômatos paracíticos apenas na face abaxial, nervuras de até 4aㅡordem, aréolas completas, F.E.V.s com 2-3 bifurcações, nervuras intersecundárias, e padrões morfológicos compartilhados entre as outras espécies de Protium. Este estudo proporcionou importantes dados a respeito da espécie de $P$. ovatum através das técnicas de diafanização foliar e por modelagem em 3D.
\end{abstract}

\section{Keywords}

F.E.V.S.

Venation

Protium ovatum

Foliar diaphanization

Foliar analysis
The work aimed to use of techniques for diaphanization and 3D mathematical modeling as contribution methods and leaf identification of Protium ovatum Engl. P. ovatum leaves were collected in a Cerrado area in Rio Verde, GO, Brazil. Leaf blades were diaphanized with toluidine blue, gentian violet, methylene blue, safranin and phenolic fuchsin. Scanning and optical micrographs, and 3D mathematical modeling were performed using negative, inverted images and $X Y Z$ filters. Important results were obtained for the accurate identification of $P$. ovatum by leaf diaphanization and with 3D mathematical devices. We observed 3 pairs of leaflets, glandular trichomes only on the adaxial face and tectorals on the abaxial, paracitic stomata only on the abaxial face, ribs of up to 4th order, complete areolas, F.E.V.s with 2-3 bifurcations, intersecondary ribs, and shared morphological patterns between the other species of Protium. This study provided important data about $P$. ovatum species through leaf diaphanization techniques and 3D modeling.

\section{INTRODUÇÃO}

O domínio Cerrado é o segundo maior em biodiversidade vegetal do Brasil, estando atrás somente do bioma Amazônico. Atualmente o Cerrado apresenta cerca de 2 milhões de $\mathrm{km} 2$ ou $22 \%$ do território brasileiro (BUENO et al., 2018). O Cerrado abrange os estados do TO, MT, GO, MG, BA, $M S, P I, R O, P R, S P, M A$ e $D F$, com encraves no $A P, R R$ e $A M$ (BUENO et al., 2018; RIBEIRO; WALTER, 2008).

Devido à extensa área de cobertura vegetal, este domínio é considerado de transição entre os demais biomas brasileiros, além de apresentar numerosas famílias botânicas como a Burseraceae. A família Burseraceae apresenta dois centros de distribuição pantropical nos continentes americano e africano (ROSALEM et al., 2017; JUDD et al., 2009). Sendo composta por 18 gêneros e cerca de 700 espécies, sendo os quatro gêneros em especial Bursera, Commiphora, Protium e Canarium (ROSALEM et al., 2017; JUDD et al., 2009). Alguns gêneros de Burseraceae produzem seiva oleosa rica em compostos voláteis como os óleos essenciais e triterpenos das séries oleano, ursano e eufano (BANEIDERA et al., 2002), apresentam também uso na produção de cosméticos, como cremes, hidratantes e na perfumaria (RUDIGER et al., 2009). Algumas espécies de Protium apresentam ações fitoterápicas comprovadas agindo em diferentes atividades como antitumoral, antineoplásica, antinociceptiva, antinflamatória, analgésica, expectorante, cicatrizante, e estimuladora do sistema nervoso central (CAMARGO et al., 2010; BANDEIRA et al., 2002).

O gênero Protium é o principal membro da família, apresentando cerca de 150 espécies distribuídas na América do Sul. E dentre essa rica biodiversidade vegetal, algumas 
espécies do gênero Protium são citadas por Lima e Piran (2005) no estado de São Paulo, estando presentes no estudo P. heptaphyllum (Aubl.) Marchand., P. kleinii Cuatrec., $P$. ovatum Engl., P. spruceanum (Benth.) Engl., e P. widgrenii Engl. No estado de Goiás foram descritas em estudo, as espécies de $P$. ovatum e $P$. heptaphyllum por Cabral et al. (2018) e por Gama et al. (2017). No estado do Mato Grosso do Sul são descritas as espécies de $C$. leptophloeos, $P$. heptaphyllum, $P$. grandifolium e $P$. ovatum por Bueno et al. (2018). A espécie $P$. icicariba é encontrada desde o Norte da Amazônia, região Nordeste até a Argentina (SIANI et al., 2004). De acordo com Bandeira et al. (2002) e Lorenzi (1972) a espécie $P$. heptaphyllum é encontrada em todo o país, e em especial na região amazônica com área representativa com $80 \%$ da população Burseraceae (MARQUES et al., 2010; SIANI et al., 2004).

A espécie Protium ovatum Engl. é conhecida popularmente por (vick-do-cerrado ou almecega) pertencente à família Burceraceae (PERIOTO et al., 2011). Sendo nativas do Brasil, ocorrendo no domínio do Cerrado e no bioma Amazônico. Possui porte arbustivo entre 0,4 a 4 m; as folhas são ovais, glabras e coriáceas; a inflorescência é do tipo em panícula, os frutos quando verdes, apresentam coloração esverdeada e vermelho quando maduros, apresentando também aroma característico (ESTEVAM et al., 2017).

$P$. ovatum é considerada planta fitoterápica, sendo amplamente utilizada pela população com ações comprovadas agindo como anti-inflamatória, imunoestimulante, antinociceptiva e antinoeplásica. A espécie também é utilizada como agente inseticida (ESTEVAM et al., 2017; DIAS et al., 2011). As folhas apresentam compostos metabólicos secundários importantes como o óleo essencial que apresenta atividade tripanossomida e antileishmanicida (ESTEVAM et al., 2017). A espécie $P$. ovatum é facilmente confundida com $P$. heptaphyllum, entretanto, algumas características a diferem como a presença de folhetos ovais laterais com base truncada ou cordada características específicas para $P$. ovatum.

O uso de plantas com características fitoterápicas, biológicas ou agrícolas devem apresentar extenso estudo de classificação e de identificação por chaves dicotômicas antes de serem aplicadas no tratamento de enfermidades, ou com ações inseticidas, moluscicidas, alelopáticas, larvicidas ou como agente fungicida. Com isso, torna-se de grande importância a determinação das características botânicas de um táxon, partindo das análises minuciosas por chave dicotômica, da anatomia e diafanização da lâmina foliar, por análise química e genética.

Outro importante ponto no estudo acurado de um espécimen vegetal aplicado na fitoterapia ou em outras áreas biológicas ou agrícolas é o estudo do material foliar que apresenta importantes informações sobre a qualidade, pureza e na distinção de um material vegetal puro ou que sofreram adição de outras partes da planta ou mesmo de outras espécies (AMARAL et al., 2003).

O estudo por diafanização foliar fornecem importantes dados para a sistemática vegetal, apresentando também meios para correta identificação e circunscrição através da arquitetura foliar das espécies dentro de uma família ou gênero botânico. A diafanização, evidencia estruturas microscópicas de grande importância, como a determinação dos níveis da descrição de nervuras, F.E.V.S, descrição do padrão das células epidérmicas, dos tipos de tricomas (tectores e glandulares), da morfologia dos estômatos dentre outros (MENEZES FILHO, 2019; MENEZES FILHO; CASTRO, 2019).

O trabalho objetivou avaliar através de uma descrição por diafanização em diferentes corantes, evidenciar as características da lâmina foliar em $P$. ovatum acrescentando assim, nos estudos anatômicos desta espécie.

\section{MATERIAL E MÉTODOS}

Foram utilizadas folhas sadias, sem ataque por insetos ou herbívoros de Protium ovatum, a coleta foi realizada nas primeiras horas da manhã entre 6 a 8 horas. A área de coleta está localizada em área de preservação permanente localizada na unidade rural da Universidade de Rio Verde, Goiás, Brasil, com as seguintes coordenadas geográficas: $17^{\circ} 47^{\prime} 15.9^{\prime \prime} \mathrm{S} 50^{\circ} 57^{\prime} 59.8^{\prime \prime} \mathrm{W}$.

A espécie foi identificada pelo Biólogo MSco. Antonio Carlos Pereira de Menezes Filho, uma exsicata foi herborizada e depositada no Herbário do IF Goiano, com o seguinte registro: HRV 1427. A técnica de diafanização foliar adotada neste estudo seguiu conforme descrito por Fonsêca, Proença e Gonçalves (2007) adaptado. As folhas foram estocadas em uma solução hidroetanólica $70 \%$ com $10 \mathrm{~mL}$ de detergente líquido, até que os pigmentos fossem completamente ou parcialmente extraídos. Em seguida, o material foi lavado em água corrente até completa remoção do fixador.

As folhas foram depositadas em bandeja de polietileno de alta densidade PEAD, e uma solução de hidróxido de sódio a $5 \%(\mathrm{~m} / \mathrm{v})$ foi acrescida lentamente até completa imersão do material. $O$ tempo neste processo foi de 12 horas. Em seguida, o material foi lavado em água corrente até completa remoção da solução de $\mathrm{NaOH}$ (5\%). O material foi novamente depositado na bandeja, e uma solução de hipoclorito de sódio a $5 \%(\mathrm{v} / \mathrm{v})$ foi acrescida até completa imersão das folhas. Este processo ficou sob descanso por 12 horas. Logo após, as folhas foram lavadas em água corrente até completa remoção 
da solução de $\mathrm{NaClO}$ (5\%). Uma série etanólica foi preparada nas seguintes concentrações 10, 30, 50, 70, 90 e 100\% (v/v). O material foliar ficou sob imersão por 1 hora em cada concentração.

Após a série etanólica, o material foi imerso em solução contendo acetato de etila (P.A - ACS) por 2 horas. Em seguida, o material foliar foi corado em diferentes corantes, solução de safranina $1 \%(\mathrm{~m} / \mathrm{v})$, solução de azul de toluidina (1\%), solução de azul de metileno (1\%), solução de fucsina fenólica e solução de violeta de genciana por 45 minutos para cada corante. O excesso de corante foi retirado com solução hidroetanólica $70 \%$ e em seguida diferenciada em acetato de etila por 24 horas sob resfriamento em geladeira a $4{ }^{\circ} \mathrm{C}$.

Cada folha foi montada entre placas finas de vidro utilizando glicerina. As lâminas foram escaneadas em impressora HP Photosmart (Mod. C4480). Em seguida, as lâminas foram avaliadas em estereomicroscópio com câmera acoplada (Mod. DI-106T), câmera Digilab (Mod. DI-5.0HD) e microscópio óptico com câmera acoplada Nikon (Mod. DI136B), câmera Digilab (Mod. DI-5.0HD). Para maiores detalhes, foi empregado o uso de modelagem matemática em 3D a partir das imagens originais com processamento no software ImageJ (versão livre 1.8.0_112). Para classificação e descrição dos padrões de nervação, foi utilizado Manual of Leaf Arquitecture (Leaf Architecture 1999), Hickey (1973; 1974) e Gonçalves e Lorenzi (2011).

\section{RESULTADOS E DISCUSSÃO}

Na Figura 1 observa-se um indivíduo de $P$. ovatum em ambiente de Cerrado stricto sensu no estado de Goiás, Brasil, em 2019.

Neste estudo foram observados indivíduos de $P$. ovatum que apresentaram tamanho médio entre 0,50 a 1,25 $\mathrm{m}$ de altura. Lima e Pirani (2005) encontraram em estudo, árvores de $P$. ovatum entre 0,4 a $4 \mathrm{~m}$ de altura. Hiura e Watanabe (2017) avaliaram o gênero Protium nas cangas da Serra dos Carajás, Pará, Brasil, onde observaram para P. pilosissimum árvores de até 6 metros de altura. Já Lima et al. (2014) estudaram a espécie $P$. spruceanum (Benth.) Engl. onde descreveram árvores com aproximadamente $20 \mathrm{~m}$ de altura.

O tempo de extração dos pigmentos clorofilianos foi de 22 dias para este estudo. A variação da extração de pigmentos variam de acordo com a camada densa ou não de lignina que recobre as folhas, principalmente espécies da flora do domínio Cerrado. Essa característica apresenta meios de sobrevivência do vegetal em ambientes com baixa pluviosidade e altas temperaturas, bem como queimadas (BARROS; SOARES, 2013).

As folhas de $P$. ovatum são do tipo concolor, pinaticomposta com raque apresentando média de 7 lâminas foliares por segmento e 3 pares de folíolos (Figura 1), são ovais, glabras e coriáceas, com base truncada ou cordada, diferenciando de P. heptaphyllum (LIMA; PIRANI, 2005). Corroborando com o estudo propostos por Rosalem et al. (2017). Entretanto, os pesquisadores encontraram plantas de P. ovatum com 3 a 5 folhetos. Hiura e Watanabe (2017) descreveram para $P$. pilosissimum folhas trifoliadas (raramente simples) e alternas, com lâmina foliar cartácea, estreito-elíptica a elíptica, com ápice acuminado, acúmen mucronado ou cuspidado com base cuneada a obtusa, margem inteira.

Figura 1. Indivíduo de Protium ovatum no período de frutificação em Cerrado stricto sensu, estado de Goiás, Brasil. Fonte: Autor

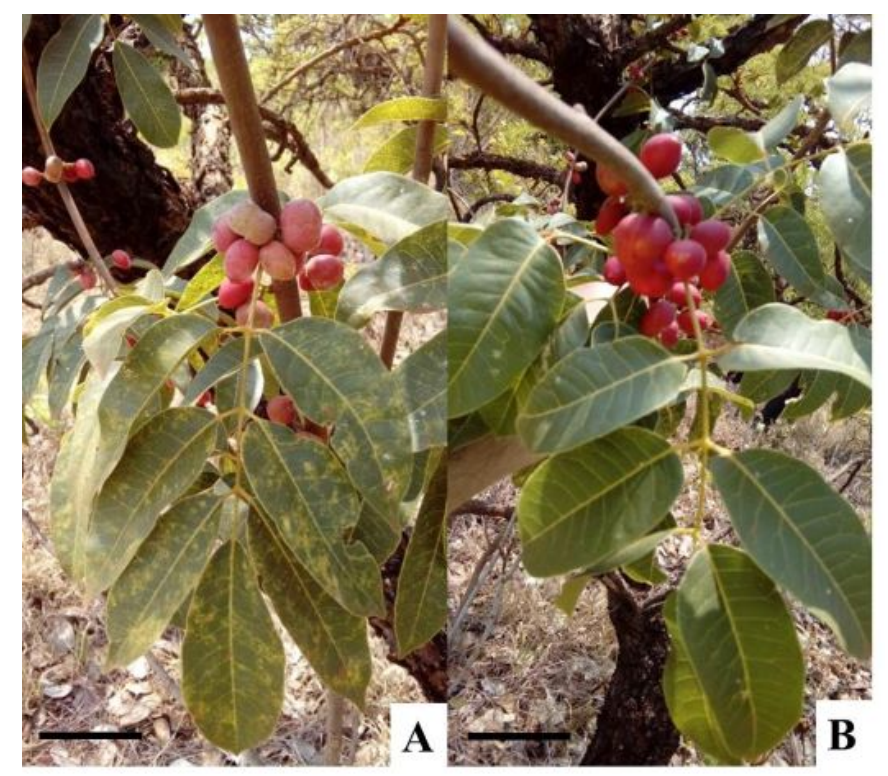

Já $P$. heptaphyllum as folhas são opostas e imparipinadas (CITÓ et al., 2006). Lima et al. (2014) descreveram para $P$. spruceanum folhas compostas com 2-3 pares de folíolos, elípticos e membranáceos, com margem sempre inteira. Rosado e Mattos (2007) observaram que a maior produção de folhas em $P$. icicariba ocorre no período chuvoso. Os botões florais surgem da intersecção dos galhos com raques observados neste estudo nos meses de agosto a outubro. Lima et al. (2014) observaram floração em $P$. spruceanum no período entre setembro a fevereiro e frutificação de novembro a maio. Os frutos de $P$. ovatum neste estudo apresentou frutificação entre outubro a janeiro de 2020. Os frutos de $P$. ovatum apresentam coloração externa verde durante o seu desenvolvimento, e quando maduros estando com coloração avermelhada apresentando grande quantidade de óleo essencial com comprimidos, liberando aroma forte, o mesmo é observado em $P$. heptaphyllum, onde os frutos são drupas de coloração avermelhada externamente e coloração branca recobrindo as sementes. 
P. ovatum apresenta margem foliar do tipo lisa, com venação foliar cladódroma. Em P. pilosissimum a nervação é do tipo broquidódroma (HIURA; WATANABE, 2017). Na Figura 1 é possível observar grupamento em cacho de frutos do tipo drupoide onde o epicarpo se abre entre 2 a 4 valvas, o mesocarpo é de cor branca, aromática, o endocarpo é lenhoso, encerrando as sementes $P$. ovatum, $P$. heptaphyllum. Na Figura 2 estão apresentadas lâminas foliares de $P$. ovatum diafanizadas coradas com safranina e fucsina fenólica. O corante safranina apresenta maior qualidade para análise visual de estruturas maiores para nervura primária sendo apenas (1), média de (32) nervuras secundárias por limbo foliar. É possível observar nervuras intersecundárias. O corante fucsina fenólica apresentou baixa qualidade visual para análise de estruturas maiores no limbo foliar, não apresentando ser uma alternativa eficiente para coloração em P. ovatum.

Siani et al. (2004) e Corrêa (1984) descrevem a especie $P$. icicariba com limbo foliar entre 3 a 5 folíolos coriáceos oblongas, pecioladas acuminada. $\mathrm{Na}$ Figura 2 estão apresentados limbos foliares de $P$. ovatum diafanizados com safranina e fucsina fenólica.

Observam-se na Figura 2 maior detalhes das estruturas maiores (nervações) nos limbos foliares corados com safranina. Já para fucsina fenólica a coloração foi intensa prejudicando a acuidade das estruturas. Na Figura 3 estão apresentadas lâminas foliares de P. ovatum coradas com azul de toluidina, violeta de genciana e azul de metileno. $O$ azul de toluidina apresentou melhor qualidade na análise visual das estruturas maiores, seguido do corante violeta de genciana.

O corante azul de metileno apresentou vários grumos em todos os limbos foliares corados, não sendo uma eficiente alternativa de corante para esta espécie Figura 3, pranchas ( $A$ e B) terceira lâmina foliar da esquerda para direita. Os corantes azuis contrastaram com melhor observação tanto para estruturas maiores (Figura 3), quanto para estruturas menores microscópicas (Figuras 9 e 10), exceto para o corante azul de metileno. Na Figura 4 estão apresentadas imagens de lâminas foliares de $P$. ovatum coradas e tratadas por imageamento na forma negativa.

$\mathrm{Na}$ Figura 4 observam-se limbos foliares corados com safranina e fucsina fenólica da esquerda para a direita em ambas as pranchas ( $\mathrm{A}$ e $\mathrm{B}$ ), tratados por imagem negativa. Pode ser observado que ao contrário da safranina que apresentou os melhores resultados para ambos os corantes vermelhos para análise visual, quando se aplica tratamento por imagem negativa o corante fucsina fenólica apresenta melhor resultado, podendo ser observado às nervuras primária, secundárias e intersecundárias e os relevos mais acentuados na face abaxial. A técnica de imagem negativa apresenta pontos positivos para análise acurada no processo de identificação foliar. Na Figura 5 podem ser observados no modo Grayscale e Fire Lut na área mediana da lâmina foliar detalhes ricos sobre a área superficial foliar.

O uso da técnica de modelagem matemática em 3D apresenta importantes resultados como observados neste estudo. $O$ uso dos pixels na formação da imagem fornece em diferentes planos ricos detalhes, como observado nas pranchas ( $A$ e $B$ ) em diferentes tratamentos utilizando o modo Grayscale e Fire Lut. Em (A) no modo Grayscale em imagem mediana do limbo foliar pode ser observado detalhes importantes das maiores estruturas, como nervação primária (np) e nervação secundária (ns). Já na prancha (B) usando o modo Fire Lut os detalhes são ainda melhores, onde pode ser observada a profundidade das nervuras e as nervuras intersecundárias (nis) em $P$. ovatum. Na Figura 6 foi utilizada a técnica de imagem invertida e com filtros $X Y Z$.

Na Figura 6 prancha $(A)$ observa-se uma área seccionada da lâmina foliar mostrando uma aréola e entre as vênulas numerosos grupamentos de estômatos abertos (seta branca) e um tricoma glandular (seta preta) próxima a uma nervura terciária (nt). Os estômatos apresentaram difícil observação na técnica de diafanização. Entretanto, quando se aplica a técnica de imagem invertida e com o auxílio de filtros $X Y Z$ prancha (B), é possível observar com maior riqueza de detalhes os estômatos e a sinuosidade da superfície foliar face abaxial. As folhas de P. ovatum são do tipo hipoestomática, apresentando estômatos apenas na face abaxial. O mesmo foi relatado em um estudo desenvolvido por Santos et al. (2015) que também observaram essa característica da família Burseraceae avaliando as lâminas foliares de P. pilosum. Na Figura 7 observa-se um fragmento da lâmina foliar corada com azul de toluidina utilizando também a técnica de imagem invertida com filtros-XYZ.

Na micrografia da Figura 7 após o processo de modelagem matemática e uso de filtros $X Y Z$ podem-se observar com maior nitidez as estruturas menores como os estômatos que para a simples análise micrográfica por diafanização, não apresentou boa eficiência em todos os corantes empregados, tanto usuais como atípicos (azul de metileno, violeta de genciana e fucsina fenólica). É possível observar as células sinuosas e inúmeros estômatos paracíticos abertos que permaneceram após a inclusão na solução extratora de pigmentos clorofilianos. Ainda na Figura 7 observa-se a junção da nervura quaternária fortemente corada. Na Figura 8 observam-se as intensidades dos filtros RGB aplicados nas lâminas foliares coradas com safranina em (A) e em azul de toluidina em (B).

Na Figura 8 observam-se em $(A)$ maior intensidade de $(R)$, seguido de (B) e por (G) nos filtros RGB para as lâminas foliares coradas com safranina. Resultados bem próximos foram obtidos também para fucsina fenólica, optando-se 
Figura 2. Lâminas foliares de $P$. ovatum diafanizadas. Em (A) face abaxial da esquerda para direita, corada com safranina e fucsina fenólica. Em (B) face adaxial da esquerda para direita, corada com fucsina fenólica e safranina. Fonte: Autor.

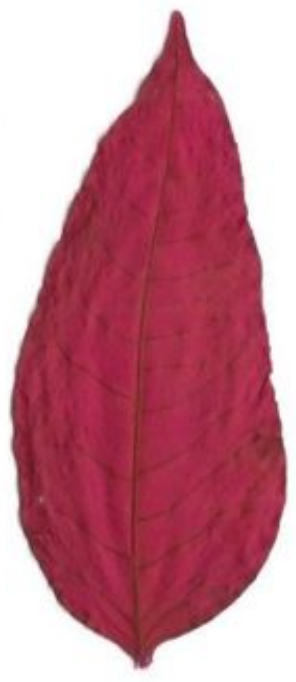

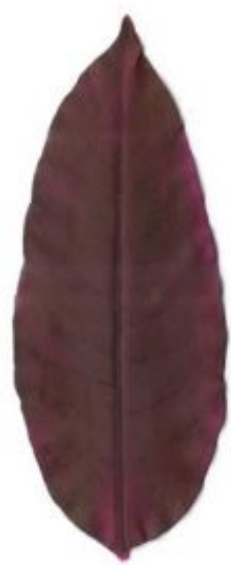

A

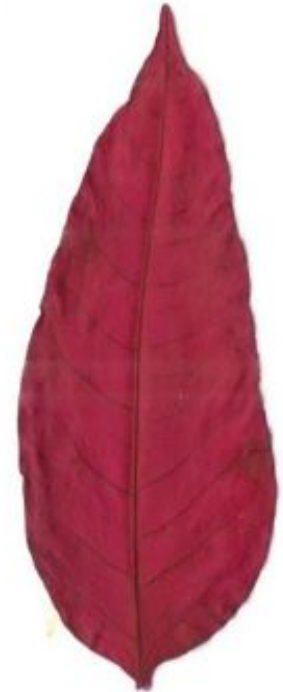

B

Figura 3. Lâminas foliares de $P$. ovatum diafanizadas. Em (A) face abaxial da esquerda para direita, corada com azul de toluidina, violeta de genciana e azul de metileno. Em (B) face adaxial da esquerda para direita, corada com azul de toluidina, violeta de genciana e azul de metileno. Fonte: Autor.

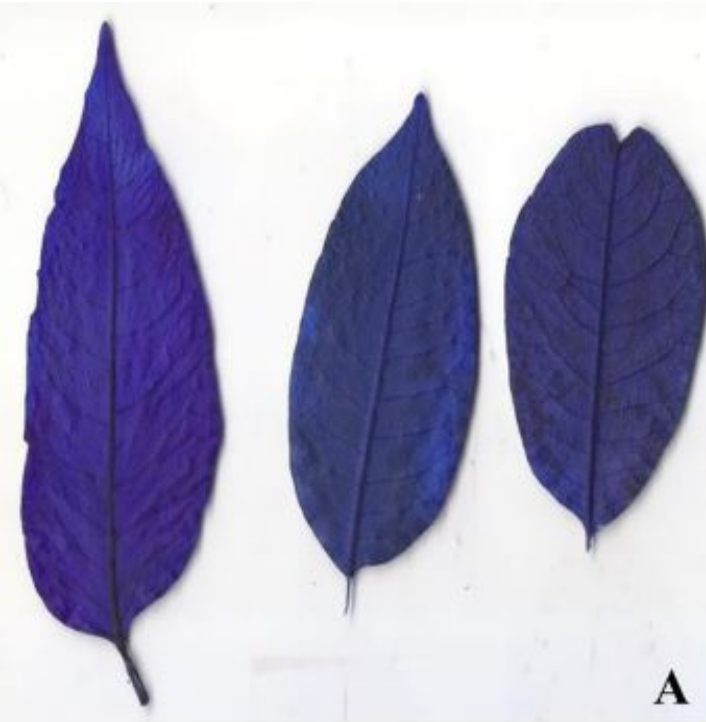

apenas pelo gráfico de intensidades dos filtros RGB para o corante habitual (safranina). Ainda na Figura 8 prancha (B) observa-se a inversão dos canais, onde a maior intensidade é observada em (B), e menores para ( $R$ e $G$ ) para lâminas coradas com azul de toluidina. O limiar em intensidade de 250 equivale à margem foliar. Neste modelo matemático com ajustes de intensidades do vermelho, verde e azul são dados importantes para a análise do corante e como o limbo foliar se comporta absorvendo e transmitindo a cor visual.

Este é o primeiro estudo que avalia os modelos matemáticos de cor para observação das três cores primárias do corante com a lâmina foliar. Comparando (A) e (B), podemos predizer que, o corante safranina apresenta maior fixação nos tecidos tanto internos quanto externos das
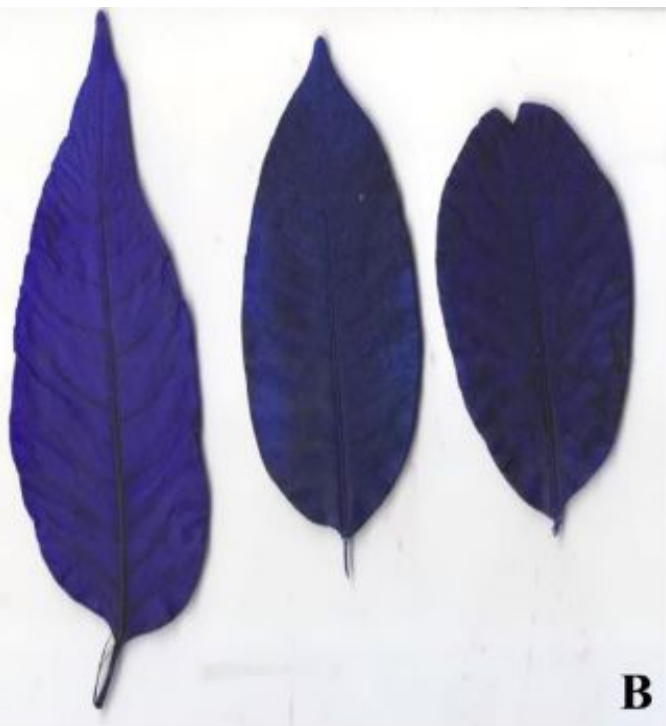

lâminas foliares, quando comparado a menor intensidade de absorção do azul de toluidina com o tecido foliar vegetal para $P$. ovatum. Esta é uma nova ferramenta para taxonomistas e botânicos que avaliam diferentes tipos de corantes que podem ser utilizados para o processo de diafanização foliar.

Na Figura 9 estão apresentadas micrografias ópticas da lâmina foliar corada com azul de toluidina, azul de metileno e safranina, mostrando tricomas glandulares cheios e os padrões de nervuras para $P$. ovatum.

Na Figura 9 estão apresentadas micrografias de $P$. ovatum onde são observadas nervuras até quarta ordem pranchas ( $A$ e B), e tricomas gandulares sobre nervuras intersecundárias e terciárias em (A). As auréolas são completas, na margem foliar apresentam arcos a partir da nervura secundária com 
Figura 4. Lâminas foliares diafanizadas de $P$. ovatum sob a forma negativa. Em (A) face adaxial e em (B) abaxial, onde se observada às nervuras primária, secundárias e intersecundárias. Barra: $10 \mathrm{~cm}$. Fonte: Autor.

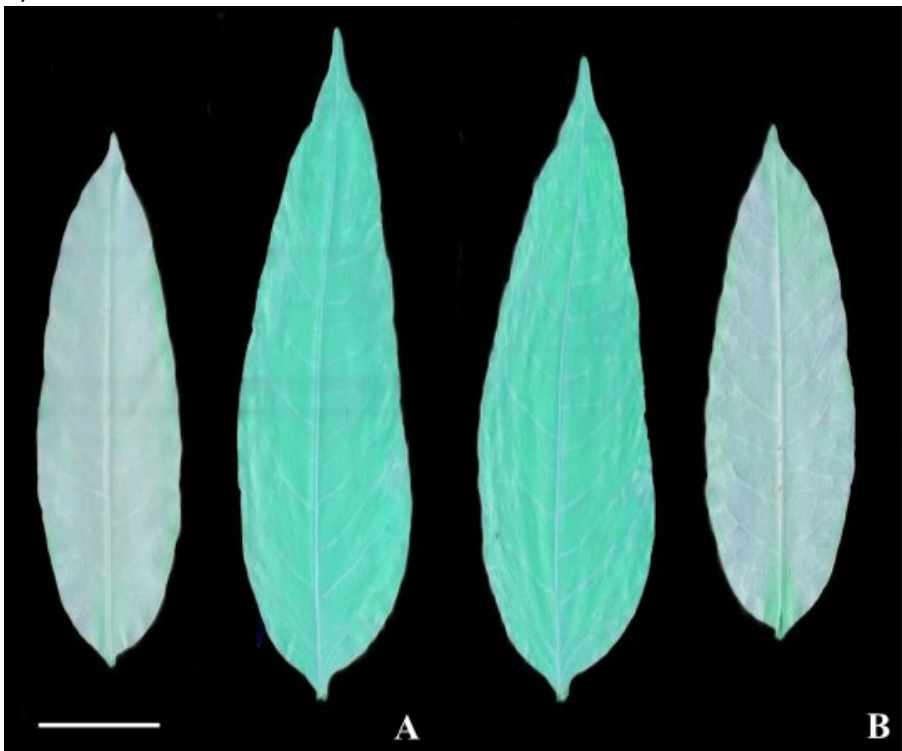

Figura 5. Perfil em área superficial de lâminas foliares de $P$. ovatum. Em $(A)$ modo Grayscale e em $(B)$ modo Fire Lut. np = nervura primária, $\mathrm{ns}=$ nervura secundária e nis = nervura intersecundária. Fonte: Autor

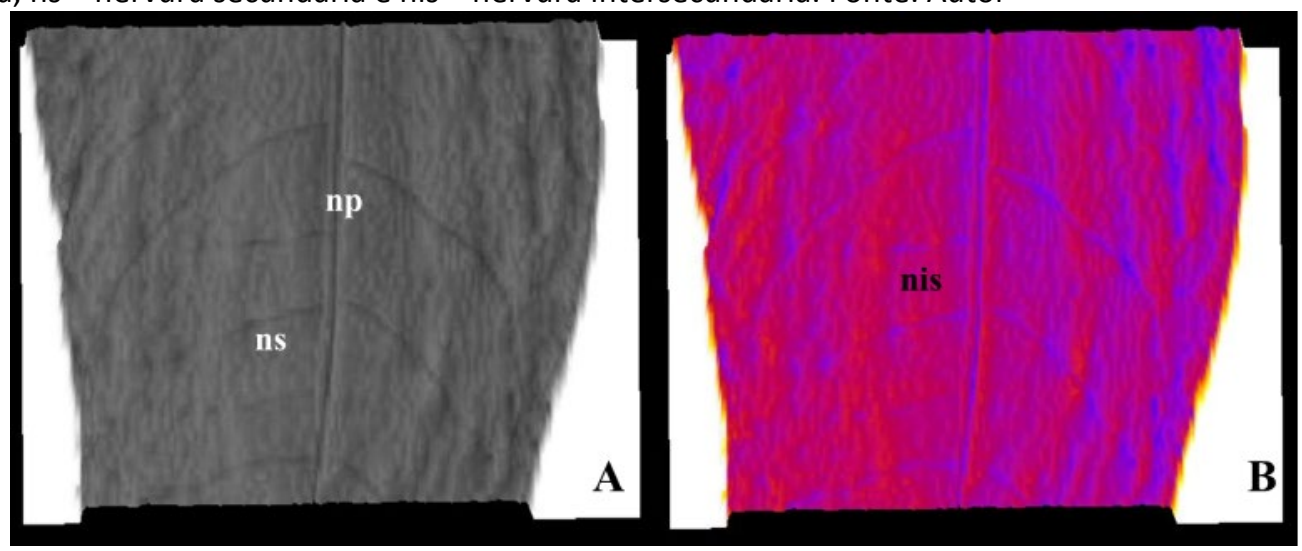

respectivas ramificações interligando as secundárias ao longo de toda lâmina foliar (B e C); os F.E.V.s apresentam 2-3 bifurcações e um tricoma glandular cheio de substância oleífera aromática na face adaxial (C). Ambos os corantes azul de toluidina e safranina coram intensamente tricomas glandulares, possivelmente os corantes possuem afinidade com as substâncias oleíferas produzidas.

Os inúmeros vegetais produtores de compostos voláteis apresentam estruturas tanto internamente quanto externamente como os tricomas secretores, idioblastos, canais e bolsas em todas as partes capazes de acumularem esses compostos (MARQUES, 2010). Em outras espécies como em $P$. heptaphyllum Bieras (2006) encontrou a presença de tricomas glandulares e tectores simples. Ainda na Figura 9, pode ser observado que a melhor reação de diafanização foi obtida pelo corante azul de toluidina para estruturas menores, não sendo o mesmo, observado nas lâminas foliares coradas com safranina. Na Figura 10 observam-se diversos cortes da área superficial do limbo foliar de $P$. ovatum.
Na Figura 10 estão apresentadas micrografias em grande e pequeno planos. Em (A) observa-se aréolas completas, nervuras terciárias, tricomas glandulares e células epidérmicas sinuosas e irregulares na face adaxial. Santos et al. (2015) observaram que em ambas as faces dos folíolos de $P$. pilosum apresentam células epidérmicas sinuosas e irregulares. A sinuosidade e irregularidade são características do gênero Protium, como também observado por Varanda (1990) para P. widgrenii, e por Rodrigues (2018) para P. paniculatum. Os tricomas glandulares são observados apenas na face adaxial, enquanto os tectores apenas na face abaxial em $P$. ovatum. Em (B) tricoma tector pluricelular com média de 3 células por tricoma e numerosos pontos em azul devido a metacromasia e deposição irregular do corante violeta de genciana. Em (C) numerosos estômatos paracíticos sendo observados apenas na face abaxial. Rodrigues (2018) descreve para as folhas de $P$. paniculatum estômatos paracíticos apenas na face abaxial. Súniga et al. (2015) encontraram para $P$. aracouchini estômatos paracíticos 
Figura 6. Micrografias ópticas em fragmento foliar abaxial de $P$. ovatum. Em (A) técnica de imagem invertida em limbo foliar corado com fucsina fenólica. Em (B) técnica de imagem invertida em filtro XYZ. ns = nervura secundária, nt = nervura terciária, $\mathrm{nq}=$ nervura quaternária, seta (branca) estômatos anomocíticos e seta (preta) tricoma glandular. Barras: (A) 65 m e em (B) $100 \mu \mathrm{m}$. Fonte: Autor

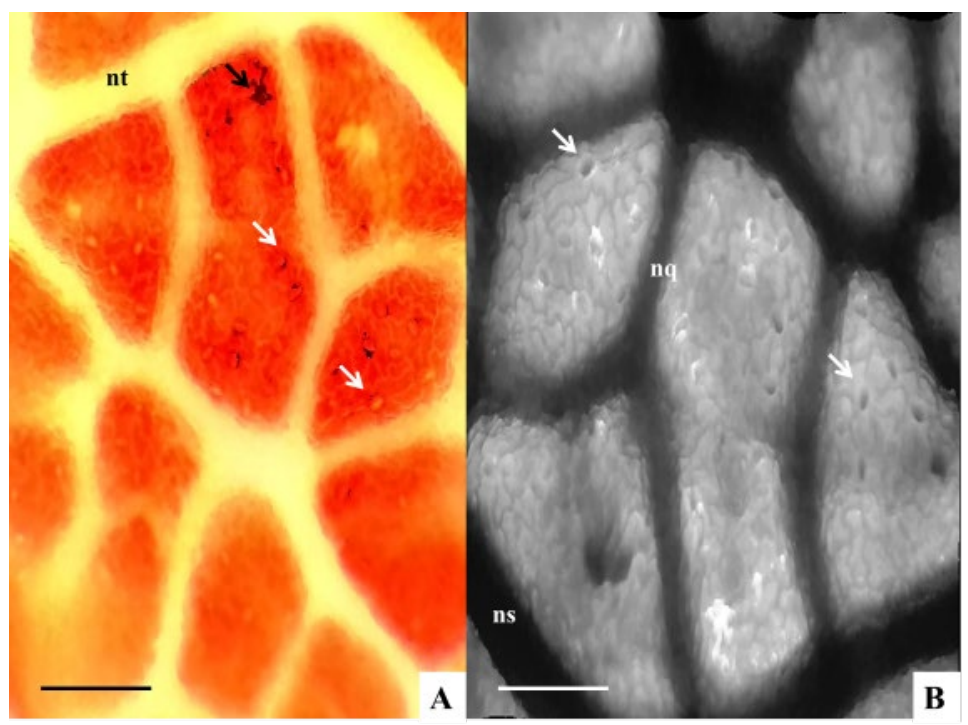

Figura 7. Fragmento de lâmina foliar de $P$. ovatum corada com azul de toluidina, sob a técnica de imagem invertida com filtro $X Y Z$. Em (A) imagens de células epidérmicas sinuosas circundando numerosos estômatos paracíticos abertos. jnq = junção da nervura quaternária. Barra: $150 \mu \mathrm{m}$. Fonte: Autor.

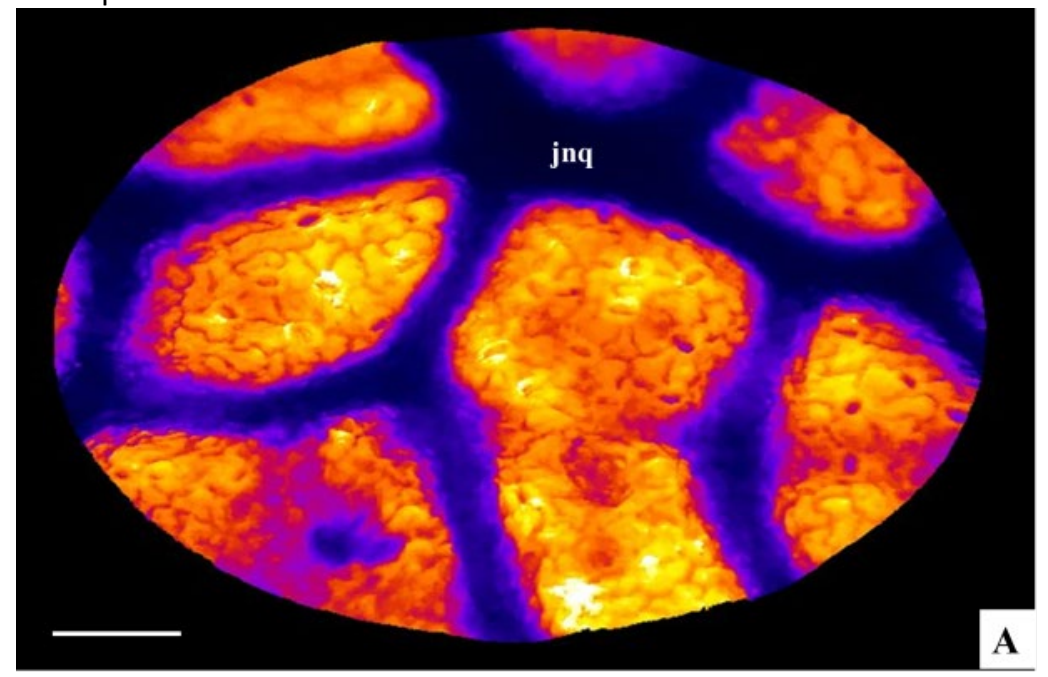

apenas na face abaxial. Já Santos et al. (2015) descreveram para $P$. pilosum a presença de estômatos do tipo paracítico e folhas hipoestomáticas com a presença desse tipo de estômatos na epiderme da face adaxial. Camargo (2009) observou a presença de estômatos anomocíticos nas espécies de $P$. apiculatum e $P$. decandrum, enquanto que para $P$. hebetalum verificou um tipo diferente de estômato classificado como braquiparacítico. Folhas hipoestomática também são descritas por Rodrigues (2018) para $P$. paniculatum.

Uma densa camada de tricomas tectores foi observada por Hiura e Watanabe (2017) em P. pilosissimum na face abaxial em especial na base da nervura primária. Lima et al. (2014) observaram que os tricomas tectores finos e eretos em $P$. spruceanum apresentaram maior densidade na nervura principal (primária) na face abaxial. Santos et al. (2015) descreveram para $P$. pilosum apenas tricomas tectores unicelulares. Os pesquisadores ainda observaram um terceiro tipo de tricomas em $P$. pilosum classificando como multicelular não ramificado composto por uma única fileira de células sendo denominada por unisseriado característica específica desta espécie.

$\mathrm{Na}$ lâmina foliar foram observados na face adaxial tricomas tectores, e apenas na face abaxial tricomas glandulares que possuem a função de secretarem compostos principalmente com características de voláteis (óleo essencial) para P. ovatum, sendo uma característica específica para a espécie. Santos et al. (2015) avaliando a anatomia foliar de $P$. pilosum observaram que em ambas as faces apresentaram tricomas tectores e glandulares. $\mathrm{O}$ óleo 
Figura 8. Intensidades dos filtros em RGB (Red = vermelho), (Blue = azul) e (Green = verde). Em (A) lâmina foliar de P. ovatum corada com safranina. Em (B) lâmina foliar corada com azul de toluidina. Fonte: Autor

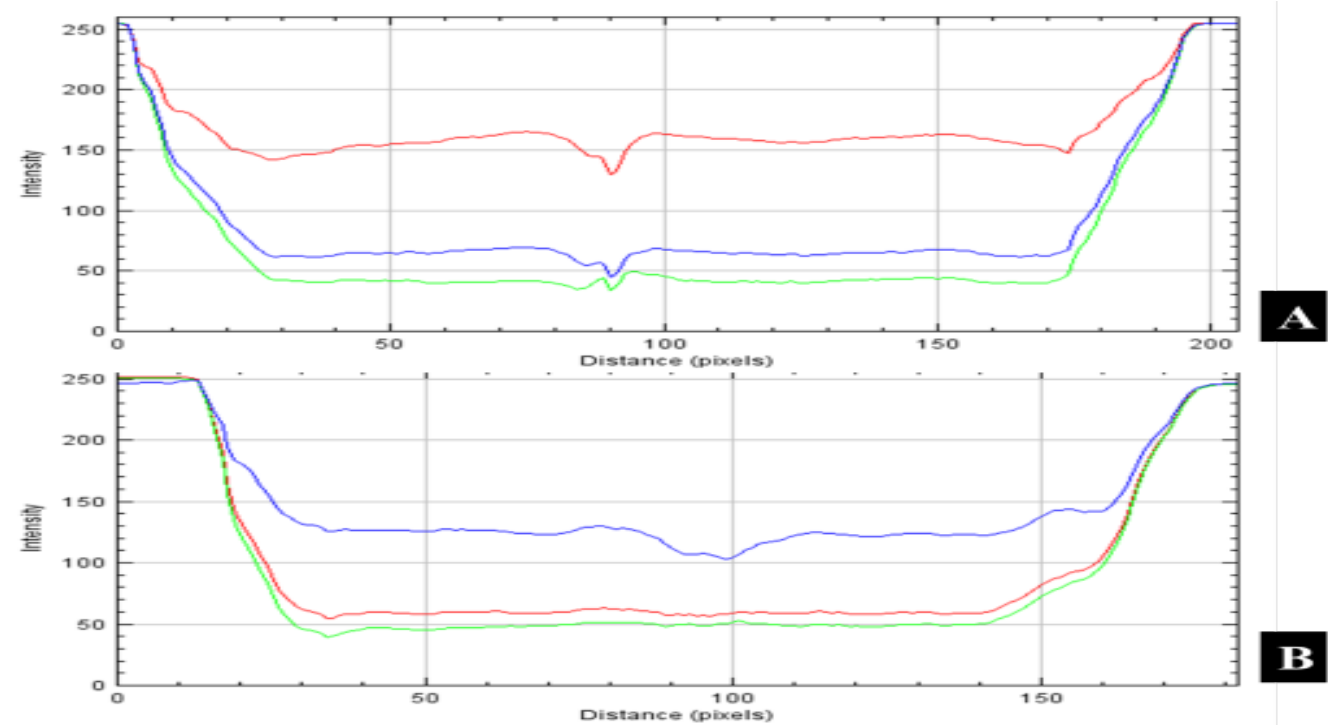

Figura 9. Lâminas foliares de P. ovatum diafanizadas. Em (A) corada com azul de toluidina, em (B) corada com azul de metileno, e em (C) safranina. $\mathrm{np}=$ nervura primária, $\mathrm{ns}=$ nervura secundária, $\mathrm{nt}=$ nervura terciária, $\mathrm{nq}=$ nervura quaternária, arc $=$ arco, are $=$ aréola, F.E.V.s, setas (branca) tricoma glandular cheio. Fonte: Autor.

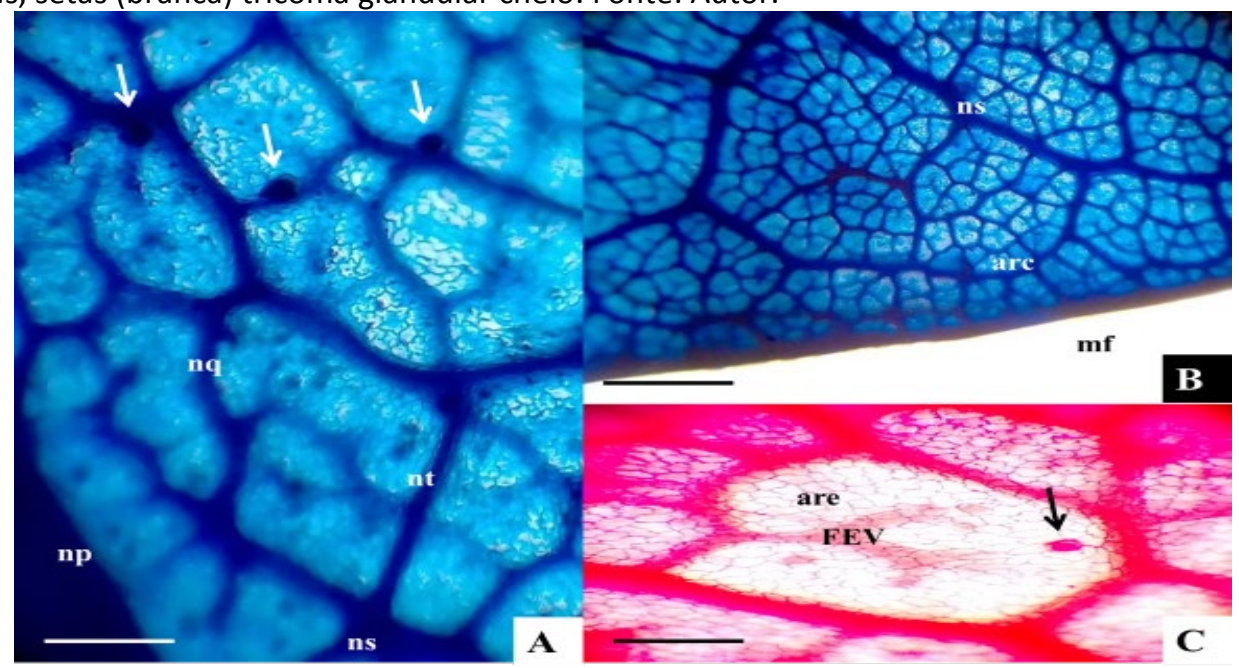

Figura 10. Lâminas foliares de P. ovatum. Em (A) corada com azul de toluidina, em (B) corada com vileta de genciana e em (C) corada com azul de metileno. $\mathrm{np}=$ nervura primária, $\mathrm{nsr}=$ nervura secundária ramificada, $\mathrm{nt}=$ nervura terciária, are $=$ aréola, setas (branca) tricoma glandular em (A) e em (B) tricoma tector pluricelular. Barras: (A) $65 \mu \mathrm{m},(B) 100 \mu \mathrm{m},(C) 150 \mu \mathrm{m}$. Fonte: Autor.

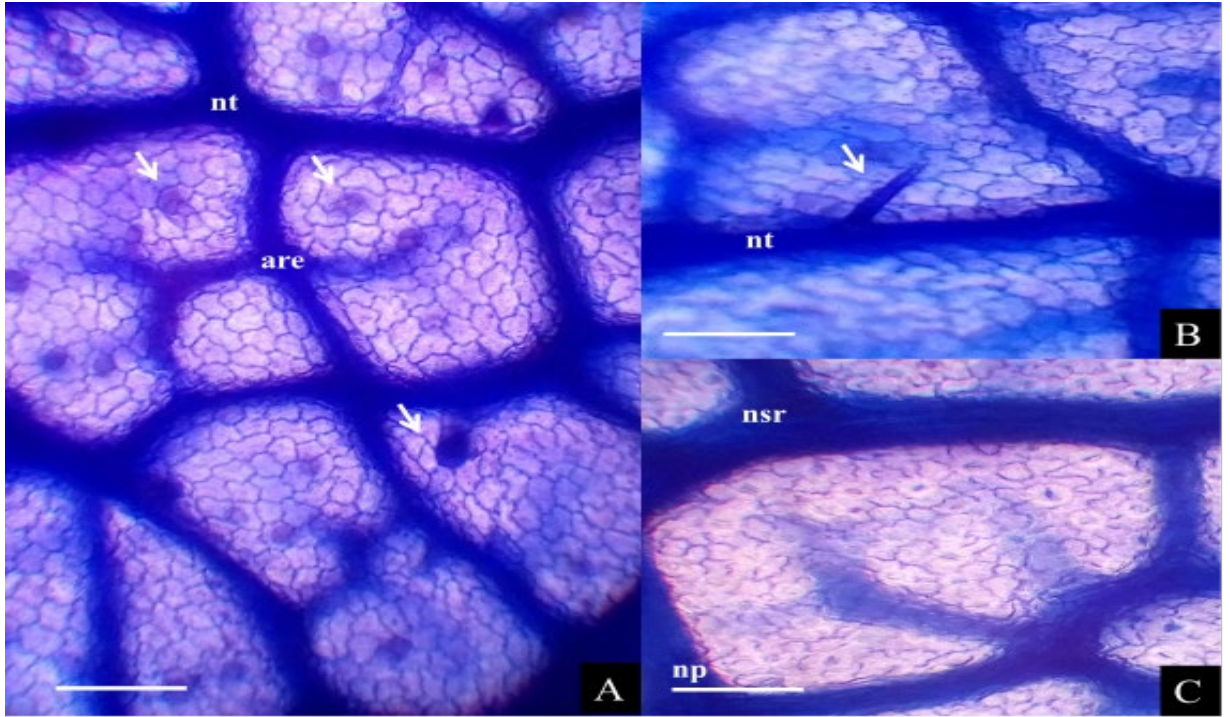


realizado por Estevam et al. (2017), 18 compostos, sendo um óleo rico em compostos sesquiterpênicos. Os pesquisadores ainda avaliaram as atividades leishmanicida, citotóxica e tripanossomida onde apresentaram importantes resultados de atividade biológica. Outra espécie semelhante é a $P$. heptaphyllum que apresenta compostos voláteis e aromáticos na lâmina foliar (BIERAS; SAJO, 2009). Cabral et al. (2018) encontraram eficiente atividade antibacteriana para o óleo essencial das folhas de $P$. heptaphyllum extraídos a partir dos tricomas glandulares e de outras estruturas internas.

Neste estudo observam-se células da epiderme adaxial plana e na face abaxial levemente plana com ondulações leves como se observa no imageamento em 3D, Figuras 6 e 7, e por micrografia óptica Figura 10. Rosalem et al. (2017) também observaram estas características em um estudo anatômico foliar em $P$. ovatum, onde também descreveram diversas hifas de fungos desconhecidos sobre a cutícula em ambas as faces. Já Bieras e Sajo (2009) observaram em P. heptaphyllum células epidérmicas sinuosas e paredes anticlinais.

Tricomas tectores são observados, sendo, entretanto esparsos na superfície da epiderme abaxial Figura 10. Tricomas tectores unicelulares e unisseriados foram observados por Rosalem et al. (2017) na face adaxial em $P$. ovatum, o mesmo não foi observado neste estudo. Rodrigues (2018) observou esse tipo de tricoma em ambas às faces foliares de $P$. paniculatum. Estudos realizados por Súniga et al. (2015) e Bieras (2006) avaliando P. heptaphyllum e $P$. aracouchini também encontraram a presença de tricomas tectores unicelulares.

\section{CONSIDERAÇÕES FINAIS}

Entre os corantes utilizados, a safranina foi o corante que apresentou os melhores resultados para estruturas maiores, entretanto, para estruturas menores os corantes azul de toluidina, fucsina fenólica e o azul de metileno apresentaram resultados satisfatórios nesta ordem. O uso das técnicas de modelagem matemática permitiu avaliar com maior acuidade as estruturas maiores e menores a partir das imagens por scanner e por micrografias ópticas, sendo uma nova técnica para estudos de macro e micro estruturas morfológicos aliados a diafanização, como observado neste primeiro estudo para $P$. ovatum e como segundo estudo dos autores.

O estudo da diafanização foliar aliada a modelos matemáticos a partir de imagens permite o fornecimento de imagens por pixels com excelente qualidade permitindo também a observação de estruturas opacas. P. ovatum apresentou características semelhantes às espécies pertencentes ao mesmo gênero, porém pode ser diferenciada pela presença de tricomas tectores pluricelulares, pois é comum encontrar tricomas glandulares e tricomas tectores unicelulares em espécies do mesmo gênero.

\section{REFERÊNCIAS}

AMARAL, F. M. M., Avaliação da qualidade de drogas vegetais comercializadas em São Luís/Maranhão. Revista Brasileira de Farmacognosia, v. 13, supl., p. 27-30, 2003.

BANDEIRA, P. N. et al. Metabólitos secundários de Protium heptaphyllum March. Química Nova, v. 25, n. 6B, p. 10781080, 2002.

BARROS, H. O., SOARES, A. A. Adaptações anatômicas em folhas de marmeleiro e velame da caatinga brasileira. Revista Ciência Agronômica, v. 44, n. 1, p. 192-198, 2013.

BIERAS, A. C., SAJO, M. G. Leaf structure of the Cerrado (Brazilian savanna) woody plants. Trees, v. 23, n. 3, p. 451471, 2009.

BIERAS, A. C. Morfologia e anatomia foliar de dicotiledôneas arbóreo-arbustivas do Cerrado de São Paulo. 2006. Tese de Doutorado. Universidade Estadual Paulista. pp 67.

BUENO, A. L. et al. Flora arbórea do Cerrado de Mato Grosso do Sul. Iheringia, série Botânica, Porto Alegre, v. 73, p. 5364, 2018.

CABRAL, R. S. C. et al. Chemical composition of essential oils from different parts of Protium heptaphyllum (Aubl.) Marchand and their in vitro antibacterial activity. Natural Product Research, p. 1-6, 2018.

CAMARGO, M. A. B. Características estomáticas em espécies arbóreas da Amazônia Central. 2009. Dissertação Mestrado em Biologia Tropical e Recursos Naturais. Universidade Federal do Amazonas.

CITÓ, A. M. G.. L. et al. Identificação de constituintes voláteis de frutos e folhas de Protium heptaphyllum Aubl. (March.). Revista Brasileira de Plantas Medicinais, v. 8, n. 4, p. 4-7, 2006.

CORRÊA, P. Dicionário das plantas úteis do Brasil e das exóticas cultivadas. Vol. 1, Imprensa Nacional, Ministério da Agricultura, Rio de Janeiro, pp. 82-83.

ESTEVAM, E. B. B. et al. In vitro antiparasitic activity and chemical composition of the essential oil from Protium ovatum leaves (Burceraceae). Annals of the Brazilian Academy of Sciences, v. 89, n. 4, p. 3005-3013, 2017.

FONSÊCA, L. C. M., PROENÇA, C. E. B., GONÇALVES, E. G. Descrição do padrão de venação foliar em Spathicarpa Hook. (Araceae). Acta Botanica Brasilica, v. 21, n. 1, p. 213221, 2007.

GONÇALVES, E. G., LORENZI, H. Morfologia Vegetal: Organografia e Dicionário llustrado de Morfologia das plantas Vasculares. 2a Ed., Instituto Plantarum de Estudos da Flora Ltda, São Paulo, 512 p. 
HIURA, A. L., WATANABE, M. T. C. Flora das cangas da Serra dos Carajás, Pará, Brasil: Burseraceae. Rodriguésia, v. 68, n. 3, p. 921-923, 2017.

HICKEY, L. J. Classification of arquitecture of dicotyledonous leaves. Botanical Gazette, v. 60, n. 1, p. 17-33, 1973.

HICKEY, L. J. Clasificación de la arquitectura de las hojas de dicotiledóneas. Boletín de la Sociedad Argentina de Botánica, v. 16, n. 1/2, p. 1-26, 1974.

JUDD, W. S. et al. Sistemática vegetal um enfoque filogenético. Artmed, Porto Alegre, pp. 437-438, 2009.

KRAUS, J. E., ARDUIN, M. Manual básico de métodos em morfologia vegetal. Rio de Janeiro, EDUR, 1997.

LEAF ARCHITECTURE WORKING GROUP. Manual of leaf architecture - Morphological description and categorization of dicotyledonous and net-veined monocotyledonous angiosperms. Washington, DC., Departament of Paleobiology, Smithsonian Institution.

LIMA, T. A. A. C. et al. Aspectos morfológicos e químicos de Protium spruceanum: Uma contribuição ao conhecimento de espécies aromáticas do bosque da ciência do INPA. Scientia Amazonia, v. 3, n. 2, p. 6-10, 2014.

LIMA, L. R., PIRANI, J. R. Burseraceae. In: Wanderley, M. G. L., Shepherd, G. J., Melhen, T. S., Martins, S. E., Kirizawa, M., Giulietti, A. M. (Eds.), Flora Fanerogâmica do Estado de São Paulo. FAPESP/RiMA, São Paulo, pp. 163-168.

LORENZI, H. Árvores Brasileiras. Plantarum Ltda., Piracicaba, 1972, p. 76.

MARQUES, D. D. et al. Chemical composition of the essential oils from two subspecies of Protium heptaphyllum. Acta Amazonica, v. 40, n. 1, p. 227-230, 2010.

MARQUES, D. D. et al. Contribuição ao conhecimento químico da flora acreana: Protium hebetatum Daly, Protium heptaphyllum (Aublet) Marchand subsp. ulei (Swat) Daly e Protium heptaphyllum (Aublet) Marchand subsp. heptaphyllum. 2010. Tese de Doutorado em Química. Universidade Federal do Ceará. Pp. 56.

MENDONÇA, R. C. et al. Flora vascular do Cerrado: Checklist com 12.356 espécies. In Cerrado: ecologia e flora (SANO, S. M., ALMEIDA, S. P., RIBEIRO, J. F. eds.). Embrapa, Planaltina, p. 417-1279, 2008.

MENEZES FILHO, A. C. P de. Descrição do padrão de venação foliar em Aristolochia esperanzae O. Kunthze (Aristolochiaceae) em diferentes corantes. Multi-Science Journal, v. 2, n. 3, 2019.

MENEZES FILHO, A. C. P de., CASTRO, C. F de. S. Análise morfológica e morfométrica dos órgãos vegetativos, composição fitoquímica dos extratos etanólicos e atividade hemolítica de Sinningia elatior (Kunth.) Chautems (Gesneriaceae). Multi-Science Journal, v. 2, n. 3, 2019.

MYERS, N. et al. Biodiversity hotspots for conservation priorities. Nature, v. 403, n. 6772, p. 853-858, 2000.

RIBEIRO, J. F., WALTER, B. M. T. As principais fitofisionomias do Bioma Cerrado. In Cerrado: ecologia e flora (SANO, S. M., ALMEIDA, S. P., RIBEIRO, J. F. eds.). Embrapa Cerrados, Planaltina, p. 151-212, 2008.

RODRIGUES, B. R. S. Anatomia foliar como ferramenta na identificação de Protium paniculatum (Engl.) Daly de áreas de manejo florestal da empresa mil madeiras preciosas. 2018. Monografia. Universidade Estadual do Amazonas. pp. 32.

ROSADO, B. H. P., MATTO, E. A. de. Variação temporal de características morfológicas de folhas em dez espécies do Parque Nacional da Restinga de Jurubatiba, Macaé, RJ, Brasil. Acta Botânica Brasilica, v. 21, n. 3, p. 741-752, 2007. ROSALEM, P. F. et al. Leaf Anatomy of Protium ovatum and its antiproliferative potential in cervical cells. Brazilian Journal of Pharmacognosy, v. 27, n. 6, p. 673-678, 2017.

SANTOS, B. N. V. et al. Anatomia foliar de Protium pilosum (Cuatrec.) Daly coletada em área de transição AmazôniaCerrado. In: III Seminário de Biodiversidade e agroecossistemas amazônicos. 13 a 16 de outubro de 2015, Alta Floresta - MT. pp.1-6.

SIANI, A. C. et al. Protium icicariba as a source of volatile essences. Biochemical Sustematic and Ecology, v. 32, n. 5, p. 477-489, 2004.

SÚNIGA, L. et al. Caracterização anatômica de Protium aracouchini (Aubl.) Marchand. ocorrente no Parque Urbano no município de Sinop-MT. In: III Seminário de Biodiversidade e Agroecossistemas Amazônicos. 13 a 16 de outubro de 2015, Alta Floresta - MT.

VARANDA, E. M. Contribuição ao estudo da anatomia foliar de espécies de mata secundária semidecídua. Boletim de Botânica, v. 12, p. 101-113, 1990.

Submissão: 09/11/2019

Aprovado para publicação: 24/01/2020 